\title{
CORRECTION
}

\section{Correction to: Influence of Single-Dose Antibiotic Prophylaxis for Early-Onset Pneumonia in High-Risk Intubated Patients}

Timothy D. Lewis ${ }^{1,2}$, Kelly A. Dehne ${ }^{1,2}$, Kathryn Morbitzer ${ }^{1,2}$, Denise H. Rhoney², Casey Olm-Shipman ${ }^{3}$ and J. Dedrick Jordan ${ }^{3^{*}}$

๑ 2018 Springer Science+Business Media, LLC, part of Springer Nature and Neurocritical Care Society

Correction to: Neurocritical Care (2018) 28:362-369

https://doi.org/10.1007/s12028-017-0490-8

Due to an error introduced during the production process, J. Dedrick Jordan's name was improperly tagged in the original publication of this article. It is tagged correctly here.

\author{
Author details \\ 1 University of North Carolina Medical Center, 101 Manning Drive, Chapel Hill, \\ NC 27514, USA. ${ }^{2}$ University of North Carolina Eshelman School of Pharmacy, \\ Chapel Hill, NC, USA. ${ }^{3}$ Division of Neurocritical Care, Departments of Neurol- \\ ogy and Neurosurgery, University of North Carolina School of Medicine, 101 \\ Manning Drive, CB \#7025, Chapel Hill, NC 27599-7025, USA.
}

Published online: 9 July 2018

\footnotetext{
*Correspondence: dedrick@unc.edu

${ }^{3}$ Division of Neurocritical Care, Departments of Neurology

and Neurosurgery, University of North Carolina School of Medicine, 101

Manning Drive, CB \#7025, Chapel Hill, NC 27599-7025, USA

Full list of author information is available at the end of the article

The original article can be found online at https://doi.org/10.1007/s1202 8-017-0490-8.
}

\section{Springer}

